\title{
Prevalence and Pattern of Canine Impaction and Its Associated Anomalies among Orthodontic Patients Attending Tertiary Care Dental Hospital in Kathmandu
}

\author{
Dr Anshu Piya,' Dr Bikash Veer Shrestha,2 Dr Anju Khapung,3 Dr Prakash Bhattarai4 \\ 2Assistant Professor, Department of Orthodontics and Dentofacial Orthopaedics, \\ Lecturer, Department of Community and Public Health Dentistry, \\ 4Professor, Department of Orthodontics and Dentofacial Orthopaedics, \\ Nepal Medical College and Teaching Hospital
}

Correspondence: Dr Ansu Piya; Email: anshupiya1@gmail.com

\section{ABSTRACT}

Introduction: Permanent canines are considered as the cornerstone of mouth. Canines are important for esthetics and function as they are located in the anterior segment of the mouth and help in tearing of food. An impacted tooth is that tooth that cannot or will not erupt into its normal functional occlusion due to some circumstances. Those impacted tooth are considered pathologic as they might lead to various problems like resorption of roots of adjacent teeth, cystic formation, and infection with partial eruption leading to pain and trismus.

Materials \& Method: All the patients (550) being treated in department of Orthodontics in Nepal Medical College from January 2017 to December 2019 were included in the study. Patients aged 13-30 years were included in the study. Clinical examinations and panoramic radiographs of patients were taken. Anterior occlusal view was done in those patients having canine impaction to determine the patterns of impaction. Data was processed in SPSS version 16.0.

Result: Among 550 orthodontic patients, 31 patients were found to have canine impaction. Among them 18 (58.1\%) were females and $13(41.9 \%)$ were males. The overall prevalence of canine impaction was found to be $5.6 \%$. Various dental anomalies were observed in the participants' radiographs, the most common being the retained deciduous teeth (54.8\%) followed by dilacerations of adjacent teeth (51.6\%). Peg shaped lateral incisors and root resorption of adjacent tooth were almost equal (22.6\%) with least being the odontomas and other impacted teeth.

Conclusion: The prevalence of canine impaction in tertiary care dental hospital in Kathmandu was found to be $5.6 \%$. Patients with impacted canines also had other dental anomalies. Knowing the prevalence of impacted canines, will encourage the community to be aware about canine impaction and educate the population about the clinical implications and the importance of performing preventive and interceptive procedures.

Keywords: Anomalies, Dilacerations, Impaction, Occlusion, Resorption.

\section{INTRODUCTION}

Permanent canines are considered as the cornerstone of mouth. Canines are important for esthetics and function as they are located in the anterior segment of the mouth and help in tearing of food. An impacted tooth is that tooth that cannot or will not erupt into its normal functional occlusion due to some circumstances. ${ }^{1-3}$ Those impacted tooth are considered pathologic as they might lead to various problems like resorption of roots of adjacent teeth, cystic formation, and infection with partial eruption leading to pain and trismus. ${ }^{4-6}$

Canines are the second most commonly impacted teeth according to descending order after third molars. ${ }^{2,3,7}$ Maxillary canine buds are the last to develop and they also have the longest root and also have to travel far from lateral of the pisiform fossa to the final position in the dental arch. ${ }^{3,7}$

Maxillary canine impaction is found to be $2-3$ times more common in females than in males. . $^{8-11}$ Impaction of permanent maxillary canine has been reported in about $1 \%$ to $3 \%$ of the population.' Maxillary canine impactions occur five times more often in Caucasians than in Asians. ${ }^{12}$ Maxillary canine impaction is found to be 10-20 times more common than mandibular canine impaction from many studies. $5,12,13$

Impaction of permanent mandibular canine is a rare developmental disturbance of eruption. ${ }^{14,15}$ Incidence of mandibular canine impaction is found to be in the range of $0.10 \%$ to $1.29 \% .6,16$ Retained deciduous teeth and supernumerary teeth have been associated with impacted transmigrated mandibular canines. ${ }^{14}$ 
From other studies, unilateral impaction is much more common than bilateral impaction in 5:1 ratio and right sided impaction is more common than left side. ${ }^{13}$ The impacted maxillary canine may be displaced labially or palatally. ${ }^{16-18}$ Incidence of palatal canine impaction is found to be 3-6 times higher on the palatal side compared to the buccal side. However, in East Asians reports show that maxillary canine impaction occurs 2-3 times higher on the buccal side compared with the palatal side. ${ }^{7.19}$

The exact etiology of canine impaction is still not known but possible causes might be due to genetic predisposition, ${ }^{20,21}$ local and systemic factors like inadequate space due to early loss of deciduous canine, ankylosis, dilacerations of root, aberrant position of erupting tooth bud, cleft of the alveolus, cystic lesions, tumors, malnutrition, idiopathic and iatrogenic causes etc 2,6 and cleido-cranial dysplasia being the most common systemic factor. Mutation in parathyroid hormone receptor 1 has been identified as one of the causes of impaction in recent studies. ${ }^{8}$

Impacted canines may cause several complications such as arch length tooth size discrepancy, migration/ displacement of adjacent teeth, esthetic problems, cystic formation, or canine ankylosis. One of the most severe complications associated with canine impaction is root resorption of adjacent teeth. As a result, this affects the longevity of adjacent teeth. Therefore, early detection and prevention would decrease the need for canine exposure and simplify orthodontic treatment. 22,23

Clinical examination of the permanent lateral incisors may help in early detection of impacted canines. Abnormal position or angulation of lateral incisor could indicate a deflected canine, which could potentially become impacted. ${ }^{13}$ The root of lateral incisors adjacent to impacted canine was found to be angulated more mesially compared to lateral incisors adjacent to normally erupted canines. ${ }^{24,25}$
Aberrant position of tooth in bone cannot be predicted at early age but the more mesially located the crown of canine in panoramic film, the more likelihood that the canine will be impacted in future. ${ }^{20,26}$ In some cases of impacted canines, expansion of the arch or local area might be necessary to create adequate space for the canine to erupt. ${ }^{24,26}$ Some cases require surgical exposure and/or extraction followed by orthodontic extrusion to facilitate eruption. ${ }^{26}$

Root length measurements of adjacent teeth can be done using panoramic radiograph but recently, cone beam computed tomography (CBCT) has been proposed as an alternative to conventional CT in the diagnosis and treatment planning of impacted teeth. .,27 $^{27}$

The aim of this study to investigate the prevalence and pattern of impacted maxillary canine among patient attending a dental hospital in Attarkhel and to evaluate the existing relation between impaction of canine and anomaly of adjacent teeth.

\section{MATERIALS AND METHOD}

All the patients being treated in department of Orthodontics from January 2017 to December 2019 were included in the study. Patients aged 13-30 years were included in the study. Patients were grouped into three groups as 13-18 years, 19-24 years and 25-30 years age group. Clinical examinations and panoramic radiographs of patients were taken. Anterior occlusal view was done in those patients having canine impaction to determine the patterns of impaction. Subjects less than 13 years (un-erupted canines could be normal) and subjects more than 30 years (they might present with loss of teeth due to caries or other problems) were excluded.7 Patients with craniofacial syndromes were excluded. Data was processed in SPSS version 16.0. The chi-squared test was used to reveal any differences in the distribution of impacted maxillary canines when stratified by gender and location lleft or

Table 1: Gender Distribution in the Selected Participants

\begin{tabular}{|c|c|c|}
\hline Gender & Number & Percentage \\
\hline Female & 18 & 58.1 \\
\hline Male & 13 & 41.9 \\
\hline Total & 31 & 100 \\
\hline
\end{tabular}

Table2: Age Distribution in the Selected Participants

\begin{tabular}{|c|c|c|}
\hline Age & Number & Percentage \\
\hline $13-18$ & 18 & 58 \\
\hline $19-24$ & 10 & 32.3 \\
\hline $25-30$ & 3 & 9.7 \\
\hline
\end{tabular}


Table 3: Location of Impaction Distribution.

\begin{tabular}{|c|c|c|c|}
\hline Impaction location & Female & Male & Total \\
\hline Upper & $17(94.4 \%)$ & $12(92.3 \%)$ & $29(93.5 \%)$ \\
\hline Lower & $1(5.6 \%)$ & $1(7.7 \%)$ & $2(6.5 \%)$ \\
\hline Left & $9(50 \%)$ & $3(23.1 \%)$ & $12(58.1 \%)$ \\
\hline Right & $8(44.4 \%)$ & $10(76.9 \%)$ & $18(38.7 \%)$ \\
\hline Bilateral & $1(5.6 \%)$ & 0 & $1(3.2 \%)$ \\
\hline Buccal & $8(44.4 \%)$ & $6(46.2 \%)$ & $14(45.2 \%)$ \\
\hline Palatal/ lingual & $10(55.6 \%)$ & $7(53.8 \%)$ & $17(54.8 \%)$ \\
\hline
\end{tabular}

Table 4: Associated Dental Anomalies and their Prevalence

\begin{tabular}{|c|c|c|c|c|c|c|c|c|}
\hline \multicolumn{2}{|c|}{ Variables } & Peg laterals & Odontoma & Retained & Impacted teeth Dilaceration & Missing & Root resorption \\
\hline \multirow{4}{*}{ Sex } & Male & $2(15.4 \%)$ & $2(15.4 \%)$ & $6(46.2 \%)$ & $1(7.7 \%)$ & $5(38.5 \%)$ & $3(23.1 \%)$ & $2(15.4 \%)$ \\
\cline { 2 - 9 } & Female & $5(27.8 \%)$ & 0 & $11(61.1 \%)$ & $1(5.6 \%)$ & $11(61.1 \%)$ & $2(11.1 \%)$ & $5(27.8 \%)$ \\
\cline { 2 - 10 } & Total & $7(22.6 \%)$ & $2(6.5 \%)$ & $17(54.8 \%)$ & $2(6.5 \%)$ & $16(51.6 \%)$ & $5(16.1 \%)$ & $7(22.6 \%)$ \\
\cline { 2 - 9 } & p-value & 0.42 & 0.09 & 0.4 & 0.81 & 0.21 & 0.37 & 0.42 \\
\hline \multirow{4}{*}{ Age } & $13-18$ & $4(22.2 \%)$ & $1(5.6 \%)$ & $10(55.6 \%)$ & $1(5.6 \%)$ & $9(50 \%)$ & $3(16.7 \%)$ & $3(16.7 \%)$ \\
\cline { 2 - 9 } & $19-24$ & $3(30 \%)$ & 0 & $6(60 \%)$ & $1(10 \%)$ & $5(50 \%)$ & $1(10 \%)$ & $3(30 \%)$ \\
\cline { 2 - 9 } & $25-30$ & 0 & $1(33.3 \%)$ & $1(33.3 \%)$ & 0 & $2(66.7 \%)$ & $1(33.3 \%)$ & $1(33.3 \%)$ \\
\cline { 2 - 9 } & Total & $7(22.6 \%)$ & $2(6.5 \%)$ & $17(54.8 \%)$ & $2(6.5 \%)$ & $16(51.6 \%)$ & $5(16.1 \%)$ & $7(22.6 \%)$ \\
\cline { 2 - 9 } & p-value & 0.55 & 0.12 & 0.72 & 0.80 & 0.86 & 0.63 & 0.65 \\
\hline
\end{tabular}

Chi square test, $p$-value $<0.05$ statistically significant

right). A p-value of $<0.05$ was accepted as statistically significant. Ethical clearance was taken from Institutional Review Committee (NMC-IRC), Nepal Medical College.

\section{RESULT}

All the patients being treated at the department of Orthodontics in Nepal Medical College from January 2017 to December 2019 were included in the study. Out of total 550 orthodontic patients, 31 patients were found to have canine impaction. Among them 18 (58.1\%) were females and 13 (41.9\%) were males (Table 1). The overall prevalence of canine impaction was found to be $5.6 \%$. Patients within the age range 1318 years showed higher percentage $(58 \%)$ of canine impaction whereas age ranged 25-30 years showed the least percentage (9.7\%) (Table 2).

More number of females showed maxillary canine impaction while mandibular canine impaction showed no gender predominance (Table 3). Left side impaction was seen to be higher among females while right side impaction and bilateral impaction showed no gender differences. Palatal impactions were significantly higher in females than in males.

Various dental anomalies were observed in the participants' radiographs, the most common being the retained deciduous teeth (54.8\%) followed by dilacerations of adjacent teeth (51.6\%). Peg shaped lateral incisors and root resorption of adjacent tooth were almost equal (22.6\%) with least being the odontomas and other impacted teeth (Table 4). Most of these anomalies were seen to be higher in females. Most of these anomalies were seen in age group 1318 years while least of these anomalies were seen in age group 25-30 years. Peg shaped laterals and root resorption was seen equally among 13-18 years and 19-24 years. Very few percentages of other anomalies were found along with canine impaction in all age groups. (Table 4)

\section{DISCUSSION}

This study was done to evaluate the prevalence and pattern of impacted canine and associated dental anomalies. Canines are considered as cornerstones of mouth due to its importance in esthetics, function and muscle balance. Canines are the second most commonly impacted teeth according to descending order after third molars. ${ }^{1,2,7}$ This high rate of maxillary impaction of canines has been attributed to the fact that they are the last tooth to develop and therefore travel long and tortuous paths before coming into functional occlusion. 8,9 
Prevalence of canine impaction is different in different population and different ethnic groups. ${ }^{4}$ This differences may be attributed to the sample selection, method of the study and area of patient selection, which suggest racial and genetic differences. ${ }^{3}$ The overall prevalence of canine impaction in this study was found to be $5.6 \%$ which was higher than that of other studies done by Kifayatullah et al ${ }^{1}$ and Verma and Valiathan. ${ }^{7}$ Similar prevalence of canine impaction was seen in another study done in Nepalese population by Upadhyaya and $\mathrm{Kafle}^{4}$ and South Western Saudi Arabian population. ${ }^{28}$ Contrary to this study, the prevalance of impacted canines was very high in Mexican population in the study done by Herrera et al. ${ }^{24}$ which was almost three times that found in Nepalese population in this study. This could be due to less number of sample size included in this study compared to other studies.

In the present study, left sided canine impaction was found to be slightly more common than right sided impaction similar to study done by Alyami et $a^{28}$ Unlike another study done by Nagpal et $a^{23}$ in which right side impaction was more. Bilateral impaction was only $5.6 \%$ in this study which is very less compared to a study done by Herrera et al in Mexican population. ${ }^{24}$ This could be due to racial and ethnic differences between Nepalese population and other population.

Female preponderance was seen in this study and the result was similar to the other studies done by Nag pal et al. ${ }^{17}$ and Altaee. ${ }^{2}$ This result is contrary to the result found in the study performed by Tassarra et al. ${ }^{29}$ The reason for female preponderance could be due to the number of female patients predominating the male patients in this study. Palatal canine impaction was found to be more than buccal canine impaction which is similar to the results in the study done by Gashi et al. ${ }^{30}$ and Kumar \& Thakur. ${ }^{31}$

Prevalence of mandibular canine impaction was very less in this study similar to a study done in Turkish population. ${ }^{5}$ Impaction of the mandibular canine is not as common as that of its maxillary counterpart. The most favourable sequence of eruption of the mandibular canines are prior to premolars. This could be the reason for the impaction of mandibular canines not being as common as maxillary canines. ${ }^{32}$

In this study, mostly microdontia and peg shaped upper lateral incisors were associated with maxillary canine impaction which was also seen in a study done by Herrera et al. ${ }^{24}$ Anomalies in lateral incisors can serve as a predictor for palatal maxillary canine impaction. ${ }^{17}$ Presence of these anomalies if recognized early might help in monitoring of the canine impaction and timely early referral in required cases.

The statistical tests done in one study ${ }^{3}$ showed a high level of significance between the relationship between sex and the location of Impaction as well as the relationship between sex and the presence of associated dental anomalies unlike this study in which the results were not statistically significant. Age and dental anomalies were also not statistically significant. No Significant associations were identified between impacted canines and dental anomalies like microdontia/peg laterals, missing teeth, dilacertion, root resorption, odontomas, other impacted teeth and retained deciduous teeth (Table 3 ).

There are some limitations of this study as the target population is very less. Further studies are needed to be done by considering more number of sample sizes with equal number of male and female population. Further studies need to be done by separating the samples on the basis of malocclusion as canine impaction could vary with different malocclusion.

\section{CONCLUSION}

The prevalence of canine impaction in tertiary care dental hopital in Kathmandu is $5.6 \%$. Patients with Impacted Canines have also shown to have some tendency to have other associated dental anomalies like microdontia or peg shaped lateral incisors, dilacerations of adjacent teeth, root resorption of adjacent teeth, retained primary teeth, other impacted teeth, odontomas and missing teeth. Knowing the prevalence of impacted canines, will encourage the community to be aware about canine impaction and educate the population about the clinical implications and the importance of performing preventive and interceptive procedures. Anomalies in lateral incisors can alarm for possibilities of canine impactions and timely early referral in required cases. 


\section{REFERENCES}

1. Kifayatullah J, Bangash Th, Ayub A and Khan D. Prevalence and patterns of impacted maxillary canine in a Peshawar sample. Pak Ora Dental J 2015; 35: 57-60.

2. Altaee $Z$. Incidence of impacted maxillary canine and associated with maxillary lateral incisor anomalies in Ramadi city. Asian j. appl. sci. tech. 2014; 5: 226-9.

3. Abutayyem H, Fouly F, Awny N, El-Marsafawy T and Ghanem RH. Prevalence of impacted maxillary canines and its associated anomalies among Dental College patients. EC Dental Science 2019; 18: 2048-58.

4. Kafle D, Shrestha S, Acharya N, Agrawal A. Prevalence of maxillary central incisor impaction and supernumerary teeth among Nepalese orthodontic patients. Orthod. J. Nepal 2015; 5: 14-6.

5. Yavuz MS, Aras MH, Buyukkurt MC, Tozoglu S. Impacted mandibular canine. J Contemp Dent Pract 2007; 8: 78-85.

6. Eid RA. Aberrant impaction of mandibular canine and lateral incisor: a Case Report. Int J Dent Oral Health 2018 ; 4: 1-6.

7. Verma N, Valiathan A. Prevalance and distribution of maxillary canine impaction in orthodontic patients. J Indian Assoc of Public Health Dent 2006; 8: 18-21.

8. Fu PS, Wang JC, WU YM. Huang TK, Chen WC, Tseng YC et al. Unilaterally impacted maxillary central incisor and canine with ipsilateral transposed canine-lateral incisor. Angle Orthodontist 2013; 83: 920-6.

9. Bjerklin $\mathrm{K}$ and Guitirokh $\mathrm{CH}$. Maxillary incisor root resorption induced by ectopic canines. A follow-up study, 13 to 28 years post treatment. Angle Orthodontist 2011;81:800-6.

10. Shapira J, Chaushu S and Becker A. Prevalence of tooth transposition, third molar agenesis, and maxillary canine impaction in individuals with Down Syndrome. Angle Orthodontist 2000; 70: 20-6.

11. Leonardi M, Armi P, Franchi L and Baccetti T. Two Interceptive Approaches to Palatally Displaced Canines: A Prospective Longitudinal Study. Angle Orthodontist 2004; 74: 581-6.

12. Schindel RH and Duffy SL. Maxillary transverse discrepancies and potentially impacted maxillary canines in mixed-dentition patients. Angle Orthodontist 2007; 77: 430-5.

13. Langberg BJ and Peck S. Tooth-size reduction associated with occurrence of palatal displacement of canines. Angle Orthodontist 2000; 70: $126-8$.

14. Jain $S$ et al. Evaluation of dental age and associated developmental anomalies in subjects with impacted mandibular canines. Angle Orthodontist 2015; 85: 638-44.

15. Kim Y, Hyun HK and Jang KT. Morphological relationship analysis of impacted maxillary canines and the adjacent teeth on 3-dimensional reconstructed CT images. Angle Orthodontist 2017; 87: 590-7.

16. Singh S, Sing AK, Sharma NK and Chaturvedi TP. Transmigration of impacted mandibular canine with the development of dentigerous cyst: Surgical extraction or orthodontic alignment? J Dent Allied Sci 2017; 6: 32-4.

17. Nagpal A, Pai KM and Sharma G. Palatal and labially impacted maxillary canine-associated dental anomalies: A comparative study. J Contemp Dent Pract 2009; 10: 67-74

18. Carvalho AB, Motta RHL, Carvalho MD. Relation between agenesis and shape anomaly of maxillary lateral incisors and canine impaction. Dental Press J Orthod 2012; 17: 83-8.

19. Kim Y, Hyun HK and Jang KT. Morphological relationship analysis of impacted maxillary canines and the adjacent teeth on 3-dimensional reconstructed CT images. Angle Orthodontist 2017; 87: 590-7.

20. Sambataro S, Baccetti T, Franchi L and Antonini F. Early predictive variables for upper canine impaction as derived from posteroanterior cephalograms. Angle Orthodontist 2005; 75: 28-34.

21. Langberg BJ and Peck S. Tooth-size reduction associated with occurrence of palatal displacement of canines. Angle Orthodontist 2000; 70: $126-8$.

22. Ngo CT, Fishman LS, Rossouw PE, Wang $H$ and Said O. Correlation between panoramic radiography and cone-beam computed tomography in assessing maxillary impacted canines. Angle Orthodontist 2018; 88: 384-9.

23. Naoumova J, Alfaro GE and Peck S. Space conditions, palatal vault height, and tooth size in patients with and without palatally displaced canines: A prospective cohort study. Angle Orthodontist 2018; 88: 726-31.

24. Herrera-Atoche JR, Agüayo-de-Pau MR, Escoffié-Ramírez M, Aguilar-Ayala FJ, Carrillo-Ávila BA, Rejón-Peraza ME et al. Impacted maxillary canine prevalence and its association with other dental anomalies in a Mexican population. Int. J. Dent. 2017; 73 : 1-4.

25. Kanavakis G, Curran KM, Wiseman KC, Barone NP, Finkleman MD, Srinivasan S et al. Evaluation of crown-root angulation of lateral incisors adjacent to palatally impacted canines. Prog Orthod.2016; 16: 1-4.

26. Smith B, Stewart K, Liu S, Eckert G and Kula K. Prediction of orthodontic treatment of surgically exposed unilateral maxillary impacted canine patients. Angle Orthodontist 2012; 82: 723-31.

27. Guarnieri R, Cavallini C, Vernucci R, Vichi M, Leonardi R, Barbato E. Impacted maxillary canines and root resorption of adjacent teeth: A retrospective observational study. Med Oral Patol Oral Cir Bucal. 2016; 21: 743--50.

28. Alyami B, Braimah R and Alharieth S. Prevalence and pattern of impacted canines in Najran, South Western Saudi Arabian population. Saudi J Dent 2019; 10: 1-6.

29. Tassara G, Lopez L, Hanke R, Tumanyan S and Picon F. Prevalence of Impacted Maxillary Canines in Puerto Rican Adolescents. Int. J Sci. Res. 2015; 3: 135-8.

30. Gashi A, Kamberi B, Ademi-Abdyli R, Perjuci F and Sahatçiu-Gashi A. The incidence of impacted maxillary canines in a Kosovar population. Int. Sch. Res. Notices 2014; 37: 1-4.

31. Kumar $\mathrm{H}$ and Thakur MK. Pattern of canine impaction in relation to lateral incisors: A retrospective study. Ann. Int. Med. Den. Res 2019; 5: 10-11.

32. Hudson APG, Harris AMP, Mohamed N. Early identification and management of mandibular canine ectopia. S.Afr.dent.j.201 1; 66 : $462-67$. 